\title{
RESEARCH
}

Open Access

\section{Pattern and risk factors of local recurrence after nephroureterectomy for upper tract urothelial carcinoma}

Xiaoying $\mathrm{Li}^{1}$, Ming Cui ${ }^{1}$, Xiaobin $\mathrm{Gu}^{1}$, Dong Fang ${ }^{2}$, Hongzhen $\mathrm{Li}^{1}$, Shangbin Qin ${ }^{1}$, Kunlin Yang ${ }^{2}$, Tianzhao Zhu ${ }^{3}$, Xuesong $\mathrm{Li}^{2}$, Liqun Zhou ${ }^{2 *}$, Xian-Shu Gao ${ }^{1 *}$ and Dian Wang ${ }^{4}$

\begin{abstract}
Purpose: This study aims to identify predictive local recurrence risk factors and site-specific local recurrence pattern of upper tract urothelial carcinoma (UTUC) with different primary tumor locations.

Methods: Three hundred and eighty-nine UTUC patients with radical nephroureterectomy were included in this study. Univariate and multivariate Cox proportional hazards regressions were performed to measure the risk of local recurrence. We also mapped the position of local recurrence sites stratified by primary tumor locations.

Results: A total of 73 patients (18.7\%) developed local recurrence within a median follow-up of 41 months (range, 3-80 months). For patients with local recurrence, the median interval of local recurrence was 9 months. Ureter tumor, multifocality, T stage, G grade, lymph node metastasis (LNM), lymph node dissection (LND), and lymph vascular invasion $(\mathrm{LVI})$ were all significantly associated with increased local recurrence by univariable analyses $(P<$ 0.05). Only multifocality, T3-4, G3, and LNM remained independent predictors of increased local recurrence by multivariable analyses. Adjuvant radiotherapy could reduce the local recurrence $(\mathrm{HR}=0.177 ; 95 \% \mathrm{Cl} 0.064-0.493, P=$ 0.001). Patients with local recurrence had poorer cancer-specific survival (4-year cancer-specific survival rate $36 \pm$ $7.5 \%$ vs $88.4 \pm 2.2 \%, P=0.000$ ). We evaluated local recurrence pattern stratified by tumor locations. Para-aortic lymph node region was the most common recurrence area for all the patients. Left-sided UTUC had more than $70 \%$ recurrent lymph nodes in the left para-aortic region (LPA). For right-sided UTUC patients, recurrent para-aortic lymph nodes distributed in the LPA (33.3\%), aortocaval (AC) (41.5\%), and right paracaval (RPC) (25.2\%) regions. Recurrence in the internal and external iliac regions was only found in the distal ureter group $(P<0.05)$. Renal pelvic fossa recurrence was only found in renal pelvic tumor $(22.2 \%, P=0.007)$. The ureter tumor bed recurrence rate was higher for ureter patients $(P=0.001)$.

Conclusions: Multifocality, T3-4, G3, and LNM are predictors of higher local recurrence rate of UTUC. Adjuvant radiotherapy can reduce local recurrence rate. Local recurrence patterns are different according to primary tumor locations.
\end{abstract}

Keywords: Upper tract urothelial carcinoma, Local recurrence, Risk factor, Primary tumor location

\footnotetext{
*Correspondence: zhouliqunmail@sina.com; doctorgaoxs@126.com

2Department of Urology, Peking University First Hospital, Peking University, Beijing, China

'Department of Radiation Oncology, Peking University First Hospital, Peking University, Beijing, China

Full list of author information is available at the end of the article
}

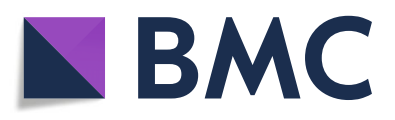

(- The Author(s). 2020 Open Access This article is licensed under a Creative Commons Attribution 4.0 International License, which permits use, sharing, adaptation, distribution and reproduction in any medium or format, as long as you give appropriate credit to the original author(s) and the source, provide a link to the Creative Commons licence, and indicate if changes were made. The images or other third party material in this article are included in the article's Creative Commons licence, unless indicated otherwise in a credit line to the material. If material is not included in the article's Creative Commons licence and your intended use is not permitted by statutory regulation or exceeds the permitted use, you will need to obtain permission directly from the copyright holder. To view a copy of this licence, visit http://creativecommons.org/licenses/by/4.0/. The Creative Commons Public Domain Dedication waiver (http://creativecommons.org/publicdomain/zero/1.0/) applies to the data made available in this article, unless otherwise stated in a credit line to the data. 


\section{Introduction}

UTUC is a relatively uncommon urinary malignant tumor and represents approximately $5 \%$ of all urothelial malignancies in the USA [1]. The incidence rate of UTUC is unusually higher in Asia. The intake of arsenic-contaminated water and the consumption of Chinese herbs are claimed to be one of the important etiologic factors for UTUC in China [2-6].

Radical nephroureterectomy (RNU) is the mainstay treatment for UTUC [7]. Several retrospective reviews have reported a locoregional failure rate varied from 6.2 to $65 \%$ in UTUC patients who underwent RNU [6, 8-13]. Factors such as multiple tumor focal, incomplete surgery, LVI, tumor grade, and T stage were found associated with local recurrence [9, 14, 15]. Template-based and complete LND was not routinely performed, which may also cause the high local recurrence rate in high-risk patients [16]. Metastasis patterns of UTUC with different primary tumor locations were different [17]. However, there is no study about the site-specific local recurrence pattern of UTUC. The role of adjuvant radiotherapy on UTUC is also not well defined [18].

Thus, in our study, we aimed to identify predictive factors of local recurrence and the effect of adjuvant radiotherapy after radical nephroureterectomy. In this study, we also analyzed the local recurrence pattern of UTUC with different primary tumor locations.

\section{Methods}

\section{Patient and treatments}

A total of 506 patients with UTUC who underwent radical nephroureterectomy from July 2010 to July 2015 in the Peking University First Hospital were reviewed. We excluded 21 patients who had a segmental resection. We also excluded 30 patients who had adjuvant chemotherapy. Sixty-six patients were lost of follow-up. Finally, a total of 389 patients were eligible for analysis. All patients underwent radical nephroureterectomy with bladder cuff resection. Laparoscopic nephroureterectomy was the standard treatment in our hospital. Open nephroureterectomy was only used for patients with wild LND. Transurethral resection of bladder tumor (TURBT) treatment was used for patients with concomitant bladder tumor during the surgery. LND was conducted when LNM was suspected in the preoperative evaluation or enlarged lymph nodes were found during surgery. The extent of our standard lymphadenectomy was the ipsilateral side of the great vessels and renal hilum for tumors of the renal pelvis, upper ureter, and middle ureter and the ipsilateral pelvic lymph nodes for tumors of the lower ureter. In some patients, lymphadenectomy was extended to the retrocaval and/or aortocaval nodes [12].
Histological diagnosis was determined according to the 2004 World Health Organization (WHO) classifications. Tumors were pathologically staged according to the Eighth American Joint Committee on Cancer (AJCC) staging system. Two hundred and seventy-eight patients (71.5\%) were pure transitional cell carcinoma; 19 patients (4.9\%) were transitional cell carcinoma with adenocarcinoma differentiation; 42 patients $(10.8 \%)$ were transitional cell carcinoma with squamous cell differentiation; 29 patients $(7.5 \%)$ were transitional cell carcinoma with necrosis; 6 patients (1.5\%) were transitional cell carcinoma with sarcoma; 15 patients (3.9\%) were other tumor types. Tumor locations were classified into two groups: renal pelvic tumor and ureter tumor. The ureter tumor group was classified into three parts: proximal ureter tumor defined as above the upper border of the sacrum, middle ureter tumor defined as from the upper to the lower border of the sacrum, and distal ureter defined as below the lower border of the sacrum [19]. Multiple tumors were defined as two or more separate tumors (not contiguous extension) within the upper urinary tract. When tumors were involved in multiple sites, primary tumor location was defined by the highest $\mathrm{T}$ stage and/or grade.

Inclusion criteria of the study were as follows: (1) pathologic diagnosis of urothelial carcinoma of renal pelvic or ureter, (2) pathological stage T1-4aN0-2 M0, (3) no primary tumor was left by positron emission tomography (PET) or CT 1 month after surgery, and (4) regular follow-up at our center. The exclusion criteria were as follows: (1) patients with previous or sequential second primary cancers (except for bladder tumor), (2) non-radical nephroureterectomy, and (3) patients with adjuvant chemotherapy.

Patients with adverse risk factors, such as T3-4, G3, or positive lymph node, were suggested to use adjuvant radiotherapy. Finally, 73 of them (18.8\%) received adjuvant radiotherapy. Adjuvant radiotherapy was performed using volumetric-modulated Arc radiotherapy (VMAT) techniques with 6-MV photons. The clinical target volume included the renal fossa, course of the ureter, abdominal, and pelvic lymph nodes. The median radiation dose was $50 \mathrm{~Gy} / 25$ fractions.

All the patients had regular follow-up every 3 months for the first 2 years after surgery, every 6 months in the next 3 years, and annually thereafter. Evaluations included a history, physical examination, blood test, urinary cytology, chest radiograph, cystoscopy, and ultrasonograms or CT/ magnetic resonance imaging (MRI) scans of the abdomen.

\section{Patterns of locoregional failure}

Locoregional recurrence was defined as lymph node relapse or surgical bed recurrence within the retroperitoneal and/or pelvis field. Diagnostic criteria for locoregional 
recurrence included the following: new adenopathy found by CT, MRI, or PET. The adenopathy definition is defined by a short axis diameter of $1 \mathrm{~cm}$ or larger in CT and/or MRI images [20-22]. The adenopathy definition is defined by PET/CT visualization of hypermetabolic activity regardless of size. The first locoregional recurrence was recorded in this study for analysis. The confluent lymph nodes were counted as one nodal recurrence. The adenopathy was reviewed and confirmed by two radiologists and were often recommended for pathologic confirmation via $\mathrm{CT}$ or ultrasound-guided biopsy. Recurrences in the lung, liver, bone, and other organs were categorized as distant metastasis. Distant lymph nodes were defined as those that occurred outside the abdomen and pelvis. Bladder relapse was not defined as a local recurrence in our study.

\section{Three-dimensional (3D) image rendering}

All CT images were reconstructed to be a 3D anatomy model including the blood vessels. Positive lymphadenopathy was contoured and standardized into a $1-\mathrm{cm}$-diameter circle. Then, the distance from the volumetric center of each lymph node to vascular bifurcation was documented in each patient with lymph node recurrence. A map of nodal recurrence consists of para-aortic, common iliac, external iliac, and internal iliac regions [23]. Para-aortic lymph nodes are further divided into three subgroups: the left of the aorta (left para-aortic or LPA), between the aorta and inferior vena cava (aortocaval or AC), or to the right of the inferior vena cava (right paracaval or RPC) [24]. We plotted all the locoregional recurrence lymph nodes on the CT image of a patient according to their relative positions to the vessels and constructed a three-dimensional local recurrence map.

\section{Statistics}

Patient characteristics were compared using either the Mann-Whitney $U$ test or the chi-square test (or the Fisher exact test for smaller cell counts) for continuous or categorical variables, respectively. We used the Kaplan-Meier to estimate cancer-specific survival, and the log-rank test was applied to compare survival curves. Variables identified as significant by the univariate analysis were considered for the multivariate analysis. Univariate and multivariate Cox proportional hazards regression analyses were performed to determine the association between risk factors and local recurrence. We used the Statistical Package for Social Sciences (SPSS, version 22.0) to analyze all data. All tests were two-sided, and $P$ values less than 0.05 were considered significant.

\section{Results}

A total of 389 patients (Table 1) were eligible for analysis. Seventy-three patients (18.7\%) had locoregional recurrence with a median follow-up time 41 months (3-80 months). The median time from surgery to local relapse was 39 months (range $1-80 \mathrm{~m}$ ) for all the patients. Among the patients with locoregional recurrence, median time from surgery to local relapse was 9 months, and 27 patients (37.0\% of 73 patients) also had distant metastasis at the same time.

The clinical characteristics, stratified according to the presence of local recurrence, are shown in Table 1. In our study, $83.8 \%$ patients used laparoscopic nephroureterectomy. Only $16.2 \%$ patients used open nephroureterectomy. Although open nephroureterectomy had a higher local recurrence rate $(25.39 \%)$, no significant difference was found in different surgical procedures $(P>0.05)$. A total of 73 patients $(18.8 \%)$ had LND in our study. The median lymph node number removed was 4 (1-36). Local recurrence rate was higher in patients with LND (34.2\% vs $15.2 \%)$. This may be because LND was only conducted when LNM was suspected in the preoperative evaluation. We can see complete transitional cell carcinoma and TCC with other differentiation had similar local recurrence rate $(P>0.005)$. On univariable analyses (Table 2$)$, multifocality, T3-4, G3, LVI, LNM, LND, and ureter tumor were all significantly associated with increased local recurrence $(P$ $<0.05$ ). On multivariable analyses, only multifocality (HR $=2.116 ; 95 \%$ CI 1.246-3.593, $P=0.006)$, T3-4 $(\mathrm{HR}=$ 2.805; 95\% CI 1.588-4.957, $P=0.000)$, G3 (HR $=2.991$; 95\% CI 1.659-5.393, $P=0.000$ ), and LNM (HR = 1.925; 95\% CI 1.053-3.521, $P=0.033$ ) remained independent predictors of increased local recurrence.

Adjuvant radiotherapy could significantly reduce local recurrence rate of UTUC on multivariable analyses (HR $=0.177 ; 95 \%$ CI $0.064-0.493, P=0.001$ ) (Table 2). Only 4 patients in the adjuvant radiotherapy group had local recurrence. Two of the four patients had lymph node recurrence out of radiation field.

Patients with isolated local recurrence received salvage radiotherapy. Chemotherapy was used for patients with both local recurrence and distant metastasis. Ninetynine patients $(25.45 \%)$ had bladder recurrence during the follow-up time in our study. Patients with bladder recurrence received TURBT or radical cystectomy. $\mathrm{Pa}$ tients with local recurrence had poorer cancer-specific survival. The 4-year cancer-specific survival (CSS) rate was only $36 \pm 7.5 \%$ in local recurrence patients compared with $88.4 \pm 2.2 \%$ in non-local recurrence patients $(P=0.000$, Fig. 1f).

We also analyzed site-specific local recurrence pattern with different primary tumor locations for patients without radiation therapy. Six patients who could not provide local recurrence image information were excluded. We stratified the other 63 local recurrent patients into four groups by primary tumor location. Twenty-seven patients had renal pelvic tumors, 3 had proximal ureter tumors, 9 had middle ureter tumors, and 24 had distal 
Table 1 Patient clinical and pathological characteristic

\begin{tabular}{|c|c|c|c|c|}
\hline Characteristics & All patients (\%) & Patients with local recurrence (\%) & Patients without local recurrence (\%) & $P$ value \\
\hline Patient number & 389 & $73(18.8)$ & $316(81.2)$ & \\
\hline Median age (range) & $69(35-88)$ & $70(37-85)$ & $69(35-88)$ & \\
\hline Age group & & & & 0.620 \\
\hline$<70$ & $202(51.9)$ & $36(49.3)$ & $166(52.5)$ & \\
\hline$\geq 70$ & $187(48.1)$ & $37(50.7)$ & $150(47.5)$ & \\
\hline Gender & & & & 0.727 \\
\hline Male & $190(48.8)$ & $37(50.7)$ & $153(48.4)$ & \\
\hline Female & $199(51.2)$ & $36(49.3)$ & $163(51.6)$ & \\
\hline Site & & & & 0.393 \\
\hline Left & $185(47.6)$ & $38(52.1)$ & $147(46.5)$ & \\
\hline Right & $204(52.4)$ & $35(47.9)$ & $169(53.5)$ & \\
\hline Location & & & & 0.042 \\
\hline Pelvic & $212(54.5)$ & $32(43.8)$ & $180(57.0)$ & \\
\hline Ureter & $177(45.5)$ & $41(56.2)$ & $136(43.0)$ & \\
\hline Concomitant bladder tumor & & & & 0.192 \\
\hline Yes & $42(10.8)$ & $11(15.1)$ & $31(9.8)$ & \\
\hline No & $347(89.2)$ & $62(84.9)$ & $285(90.2)$ & \\
\hline Tumor type & & & & 0.599 \\
\hline Complete TCC & $278(71.5)$ & $54(74.0)$ & $224(70.9)$ & \\
\hline TCC with other differentiation & $111(28.5)$ & $19(26.0)$ & $92(29.1)$ & \\
\hline Surgical procedure & & & & 0.088 \\
\hline Laparoscopic nephroureterectomy & $326(83.8)$ & $57(78.1)$ & $269(85.1)$ & \\
\hline Open nephroureterectomy & $63(16.2)$ & $16(21.9)$ & $47(14.9)$ & \\
\hline Lymph vascular invasion & & & & 0.009 \\
\hline Yes & $58(14.9)$ & $18(24.7)$ & $40(12.7)$ & \\
\hline No & $331(85.1)$ & $55(75.3)$ & $276(87.3)$ & \\
\hline Tumor grade & & & & 0.000 \\
\hline G1 & $6(1.6)$ & 0 & $6(1.9)$ & \\
\hline G2 & $209(54.4)$ & $17(23.6)$ & $192(61.5)$ & \\
\hline G3 & $169(44.0)$ & $55(76.4)$ & $114(36.5)$ & \\
\hline Pathological stage & & & & 0.000 \\
\hline $\mathrm{T} 1$ & 125 (32.6) & $9(12.3)$ & $116(36.7)$ & \\
\hline $\mathrm{T} 2$ & $121(31.5)$ & $15(20.5)$ & $105(33.3)$ & \\
\hline T3 & $129(33.6)$ & $48(65.8)$ & $87(27.5)$ & \\
\hline T4 & $9(2.3)$ & $1(1.4)$ & $8(2.5)$ & \\
\hline Lymph node detection & & & & 0.000 \\
\hline No & $316(81.2)$ & $48(65.8)$ & $268(84.8)$ & \\
\hline Yes & $73(18.8)$ & $25(34.2)$ & $48(15.2)$ & \\
\hline Lymph node involvement & & & & 0.000 \\
\hline $\mathrm{Nx}$ & $316(81.2)$ & $48(65.8)$ & $268(84.8)$ & \\
\hline No & $43(11.1)$ & $9(12.3)$ & $34(10.8)$ & \\
\hline N1 & $11(2.8)$ & $4(5.5)$ & $7(2.2)$ & \\
\hline N2 & $19(4.9)$ & $12(16.4)$ & $7(2.2)$ & \\
\hline
\end{tabular}


Table 1 Patient clinical and pathological characteristic (Continued)

\begin{tabular}{|c|c|c|c|c|}
\hline Characteristics & All patients (\%) & Patients with local recurrence (\%) & Patients without local recurrence (\%) & $P$ value \\
\hline Multifocality & & & & 0.013 \\
\hline No & $321(82.5)$ & $53(72.6)$ & $268(84.8)$ & \\
\hline Yes & $68(17.5)$ & $20(27.4)$ & $48(15.2)$ & \\
\hline Margin & & & & 0.189 \\
\hline Positive margin & $12(3.1)$ & $4(5.5)$ & $8(2.5)$ & \\
\hline Negative margin & 377 (96.9) & $69(94.5)$ & $308(97.5)$ & \\
\hline Adjuvant radiotherapy & & & & 0.014 \\
\hline Yes & $57(14.7)$ & $4(5.5)$ & $53(16.8)$ & \\
\hline No & $332(85.3)$ & $69(94.5)$ & $263(83.2)$ & \\
\hline
\end{tabular}

ureter tumors. Table 3 shows the local recurrence patterns of UTUC patients with different primary locations. Lymphatic recurrence was the main local recurrence type. The para-aortic lymph node region was the most common recurrence area ( $73 \%$ of all the patients). Common iliac lymph node region was the second common recurrence region for all the patients $(31.7 \%$ of all the patients). Recurrences in the internal and external iliac regions were only found in distal ureter tumor $(16.7 \%$ of distal ureter tumor, $P=0.018$ ). None of the patients in the ureter tumor group had renal fossa recurrence. Renal pelvic fossa recurrence only occurred in the renal pelvic tumor $(22.2 \%$ of renal pelvic tumor, $P=0.007)$. The ureter tumor bed recurrence rate was higher in ureter tumor $(45.8 \%$ in distal ureter, $22.2 \%$ in middle ureter, $66.7 \%$ in proximal ureter, $P=0.001$ ).

A total of 249 recurrent lymph nodes were recorded. Table 4 shows the distribution number of local recurrence lymph nodes. Most of the recurrent lymph nodes were in the para-aortic lymph node region (84.7\%). In the renal pelvic group, more than $90 \%$ of all the recurrence lymph nodes were in the para-aortic region. In the proximal ureter group, the ratio was $88.9 \%$. In the middle and distal ureter tumor groups, the recurrent para-aortic lymph node ratios decreased $(84 \%$ and $75.3 \%$ respectively; Table 4 ). Thus, we plotted all the local recurrence lymph nodes on the CT image of a patient according to their relative positions to vessels and constructed a three-dimensional local recurrence map (Fig. 2 shows the local recurrence lymph node distribution stratified by primary tumor location).

We also investigated the features of para-aortic lymph node recurrence pattern for left- and right-side UTUC patients. Left-side tumor patients had totally 76 recurrent lymph nodes in the para-aortic region. Of these, 55 (72.4\%) were located at LPA, 13 (17.1\%) were located at $\mathrm{AC}$, and $8(10.5 \%)$ were located at RPC. Right-side tumor patients had 135 recurrent lymph nodes in the para-aortic region: 45 (33.3\%) were located at LPA, 56 (41.5\%) were located at AC, and 34 (25.2\%) were located at RPC region. Our study found that most of the recurrent lymph nodes of left-sided UTUC patients occurred in the LPA region. For right-sided UTUC patients, recurrent lymph nodes in the para-aortic region were distributed in the LPA, AC, and RPC regions (Fig. 3).

\section{Discussion}

RNU is the standard treatment of UTUC. The 5-year cancer-specific survival of early stage $(\leq \mathrm{pT} 2 \mathrm{~N} 0)$ UTUC patients treated with RNU was fair (74.7\%), the rates dramatically decreased in patients with advanced disease (pT3, 54.0\% and pT4, 12.2\%) or nodal involvement $(35.5 \%)[25,26]$.

Bladder, local, and distant recurrences were the major recurrence types after RNU [17]. Approximately 30\% of patients with UTUC will have bladder recurrence (BR) $[27,28]$. Series of studies have been done on the prognosis and risk factors of bladder recurrence after surgery $[28,29]$. Our previous study found lower tumor grade, tumor multifocality, concomitant carcinoma in situ, and tumors located in the lower ureter were significant risk factors of bladder recurrence after RNU [27]. We also mapped the bladder recurrence sites of UTUC by primary tumor locations. We found most bladder recurrences occurred around the site of surgery and the posterior wall [30].

About 20-30\% UTUC patients may have retroperitoneal and/or pelvis field relapse after RNU [17, 31]. In the advanced stage, the local recurrence rate may reach up to $65 \%$ [9]. $\mathrm{T}$ stage and multifocality were associated with increased local recurrence $[6,9,31]$. Effects of other factors such as incomplete surgery, venous invasion, G stage [31], and tumor locations [15] on local recurrence were debated. In UTUC, template-based lymphadenectomy appears to improve CSS and reduces the risk of local recurrence in patients with advanced tumor stage [16]. But nowadays, LND is not routinely performed during RNU [18, 32]. The effects of LND and LNM status on local recurrence were seldom analyzed in previous studies. In our study, the LND rate $[6,33]$ and 
Table 2 Univariable and multivariable Cox regression analyses predicting local recurrence in 389 patients who underwent a radical nephroureterectomy for upper tract urothelial carcinoma

\begin{tabular}{|c|c|c|c|c|c|c|}
\hline \multirow[t]{2}{*}{ Variables } & \multicolumn{3}{|c|}{ Univariate analyses } & \multicolumn{3}{|c|}{ Multivariate analyses } \\
\hline & $\mathrm{HR}$ & $95 \% \mathrm{Cl}$ & $P$ value & $\mathrm{HR}$ & $95 \% \mathrm{Cl}$ & $P$ value \\
\hline Age $>70$ years & 1.125 & $0.771-1.78$ & 0.615 & & & \\
\hline \multicolumn{7}{|l|}{ Gender } \\
\hline Male & 1.121 & $0.708-1.775$ & 0.626 & & & \\
\hline Female & 1 & & & & & \\
\hline \multicolumn{7}{|l|}{ Site } \\
\hline Left & 1.213 & $0.766-1.92$ & 0.409 & & & \\
\hline Right & 1 & & & & & \\
\hline \multicolumn{7}{|l|}{ Location } \\
\hline Pelvic & 0.625 & $0.394-0.993$ & 0.047 & 0.703 & $0.427-1.155$ & 0.164 \\
\hline Ureter & 1 & & & & & \\
\hline \multicolumn{7}{|l|}{ Focality } \\
\hline Multifocality & 2.005 & $1.226-3.446$ & 0.006 & 2.116 & $1.246-3.593$ & 0.006 \\
\hline Unifocality & 1 & & & & & \\
\hline \multicolumn{7}{|l|}{ Tumor type } \\
\hline TCC with other differentiation & 0.921 & $0.546-1.555$ & 0.759 & & & \\
\hline Complete TCC & 1 & & & & & \\
\hline \multicolumn{7}{|l|}{ T stage } \\
\hline T3-4 & 4.153 & $2.554-6.78$ & 0.000 & 2.805 & $1.588-4.957$ & 0.000 \\
\hline $\mathrm{T} 1-2$ & 1 & & & & & \\
\hline \multicolumn{7}{|l|}{ Tumor grade } \\
\hline G3 & 4.674 & $2.744-7.963$ & 0.000 & 2.991 & $1.659-5.393$ & 0.000 \\
\hline G1-2 & 1 & & & & & \\
\hline \multicolumn{7}{|l|}{ LND } \\
\hline Yes & 2.802 & $1.727-4.548$ & 0.000 & 1.129 & $0.547-2.334$ & 0.742 \\
\hline No & 1 & & & & & \\
\hline \multicolumn{7}{|l|}{ Surgical procedure } \\
\hline Laparoscopic nephroureterectomy & 0.678 & $0.389-1.181$ & 0.678 & & & \\
\hline Open nephroureterectomy & 1 & & & & & \\
\hline \multicolumn{7}{|l|}{ LNM } \\
\hline Yes & 5.017 & $2.872-2.163$ & 0.000 & 1.925 & $1.053-3.521$ & 0.033 \\
\hline No & 1 & & & & & \\
\hline \multicolumn{7}{|l|}{ LVI } \\
\hline Yes & 2.12 & $1.245-3.612$ & 0.006 & 1.202 & $0.671-2.151$ & 0.536 \\
\hline No & 1 & & & & & \\
\hline \multicolumn{7}{|l|}{ Concomitant bladder tumor } \\
\hline Yes & 1.602 & $0.843-3.042$ & 0.150 & & & \\
\hline No & 1 & & & & & \\
\hline \multicolumn{7}{|l|}{ Positive margin } \\
\hline Yes & 2.053 & $0.749-5.63$ & 0.162 & & & \\
\hline No & 1 & & & & & \\
\hline \multicolumn{7}{|l|}{ Adjuvant radiotherapy } \\
\hline Yes & 0.313 & $0.114-0.861$ & 0.024 & 0.177 & $0.064-0.493$ & 0.001 \\
\hline No & 1 & & & & & \\
\hline
\end{tabular}


A

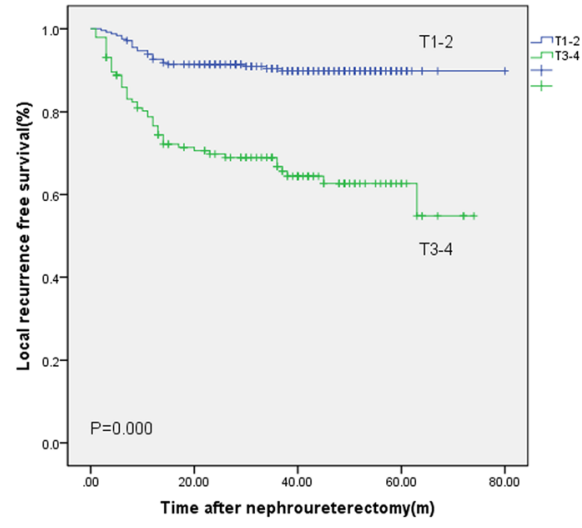

C

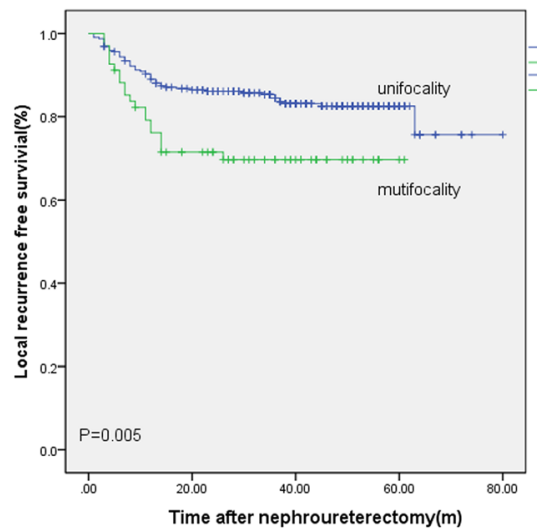

$E$

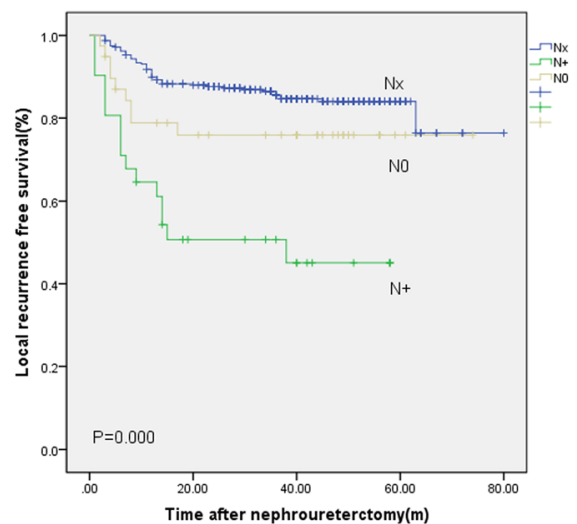

B

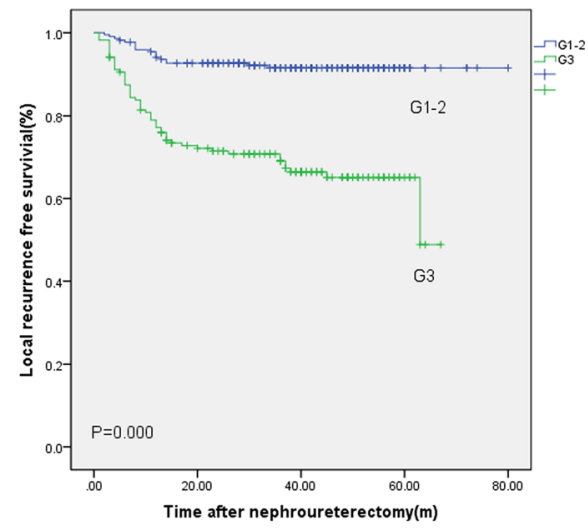

D

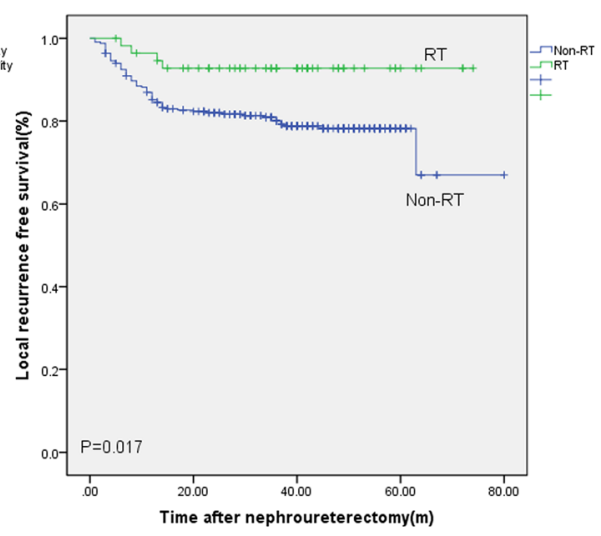

$\mathrm{F}$

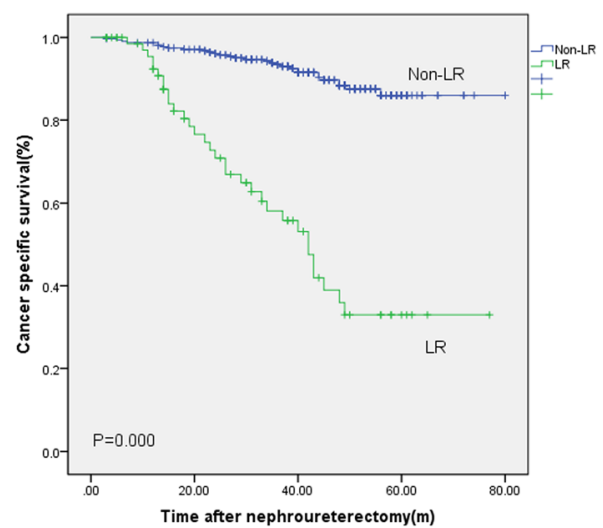

Fig. 1 The Kaplan-Meier survival curves of local recurrence-free survival stratified by T stage (a), G grade (b), multifocality (c); radiation therapy (RT) (d); lymph node status (e); cancer specific-free survival stratified by local recurrence (LR) (f)

extent of our lymphadenectomy [34] were consistent with other studies. It was interesting that patients who underwent LND had a higher local recurrence rate $(34.2 \%$ vs $15.2 \%, P<0.05)$ in our study. Based on previous literature, adequate lymph nodes removed should be more than eight [35]. But in our study, the median lymph node number removed was 4 (1-36). Only $27.4 \%$ (twenty of seventy- three) patients had their lymph nodes removed more than eight times. This indicated the LND extent and lymph node number removed nowadays were not enough.

Adjuvant radiotherapy may benefit patients with high local recurrence factors. However, there were relatively little clinical pieces of evidence supporting the efficacy of adjuvant radiotherapy for UTUC. The effects of 
Table 3 Local recurrence rate of UTUC with different primary tumor locations

\begin{tabular}{llllll}
\hline Local relapse region & $\begin{array}{l}\text { All patients } \\
(N=63)\end{array}$ & $\begin{array}{l}\text { Renal pelvic } \\
(N=27)\end{array}$ & $\begin{array}{l}\text { Proximal ureter } \\
(N=3)\end{array}$ & $\begin{array}{l}\text { Middle ureter } \\
(N=9)\end{array}$ & $\begin{array}{l}\text { Distal ureter } \\
(N=24)\end{array}$ \\
\hline Para-aortic lymph node & $46(73.0 \%)$ & $22(81.5 \%)$ & $3(100 \%)$ & $8(88.9 \%)$ & $13(54.2 \%)$ \\
Common iliac lymph node & $20(31.7 \%)$ & $7(25.9 \%)$ & $2(66.7 \%)$ & $3(33.3 \%)$ & $8(33.3 \%)$ \\
Internal iliac lymph node & $4(6.3 \%)$ & $0(0 \%)$ & $0(0 \%)$ & $0(0 \%)$ & $4(16.7 \%)$ \\
External iliac lymph node & $5(7.9 \%)$ & $0(0 \%)$ & $0(0 \%)$ & $0(0 \%)$ & $4(16.7 \%)$ \\
Renal fossa & $6(9.5 \%)$ & $6(22.2 \%)$ & $0(0 \%)$ & $0(0 \%)$ & 0.099 \\
Ureter bed & $16(25.4 \%)$ & $1(3.7 \%)$ & $2(66.7 \%)$ & $2(22.2 \%)$ & $11(45.8 \%)$ \\
\hline
\end{tabular}

adjuvant radiotherapy were argued in previous studies. Some studies found adjuvant radiation treatment had no benefit for local recurrence control [10, 36]. This may because they enrolled small and heterogeneous populations. For example, patients in radiotherapy group had a higher positive surgical margin rate in Huang's study [36]. Thirty-three of 126 patients had residual tumor in Ozsahin's study [10]. Other studies found adjuvant radiotherapy could improve local control in advanced stage UTUC patients. Jwa [37] found adjuvant radiotherapy could improve local recurrence-free survival, and Chen [38] found a benefit to adjuvant radiotherapy in overall survival. Recently, one study found in patents with pT3bN0-x UTUC, adjuvant radiotherapy alone was found to significantly reduce not only local recurrence but also distant metastasis and improve overall survival [39]. Their result suggested that adjuvant radiotherapy for local treatment might be helpful in controlling occult remnant diseases. The rationale of using adjuvant radiotherapy is to reduce local recurrence and potentially to halt distant disease progression and delay metastasis which may improve overall survival. Although guidelines have no suggestions of adjuvant radiotherapy. After recognizing the high local recurrence rate in advanced stage UTUC patients [9], our institutions have actively conducted adjuvant treatments such as radiotherapy or chemotherapy in patients with pT3, positive lymph node or G3 since 2011. Most of the patients refused to have adjuvant chemotherapy after surgery for fear of kidney function damage, some of them chose adjuvant radiotherapy. In our study, adjuvant radiotherapy group had more T3-4, G3, and LVI. These factors were all related with higher local recurrence in our study (Supplementary table). However, the local recurrence rate in the adjuvant radiotherapy group was lower. Adjuvant radiotherapy could reduce local recurrence rates even after multivariable analyses $(P<0.05)$. Our study also found patients with local recurrence had poor survival prognosis. Adjuvant radiotherapy may benefit high-risk patients with not only local control but also survival prognosis. Prospective study is needed on whether adjuvant radiotherapy can improve survival prognosis of patients with high-risk factors.

The precise understanding of local recurrence risk factors can assist clinicians in clinical risk stratification, adjuvant radiotherapy option, and surveillance arrangement. Efficacy of the postoperative radiation therapy depends on accurate delineation of clinical target volume to eradicate microscopic disease in the surgical bed while adjacent organs can be spared from high-dose irradiation with minimal toxicities. The upper urothelial tract is a large area; lymphatic drainage of the ureter and renal pelvis is different. The lymphatic of the renal pelvis drained along the renal vessels, whereas the lymphatic drainage of the ureter was segmented and diffuse [40]. For UTUC patients with template LND, UTUC with different primary site had different lymph node metastases patterns [12]. Lymph node metastasis rates in hilar and para-aortic region were higher for primary tumors of renal pelvic and proximal ureter. External and internal iliac lymph node metastasis rates were relatively higher for middle and distal ureter $[12,13]$. Results from several small series suggested different patterns of local failure of UTUC based on location of the primary cancer in the upper urothelial tract $[13,15$, 17, 41]. Tanaka found renal pelvic and proximal ureter patients had higher abdomen cavity local recurrence rates (88.2\% and 90.9\%, respectively). Distal (73.3\%) and middle (36.8\%) ureter patients had a higher prevalence of local

Table 4 Local recurrence lymph node number of UTUC with different primary tumor locations

\begin{tabular}{llllll}
\hline Local relapse region & $\begin{array}{l}\text { All patients } \\
(N=249)\end{array}$ & $\begin{array}{l}\text { Renal pelvic } \\
(N=109)\end{array}$ & $\begin{array}{l}\text { Proximal ureter } \\
(N=18)\end{array}$ & $\begin{array}{l}\text { Middle ureter } \\
(N=25)\end{array}$ & $\begin{array}{l}\text { Distal ureter } \\
(N=97)\end{array}$ \\
\hline Para-aortic lymph node & $211(84.7 \%)$ & $101(92.7 \%)$ & $16(88.9 \%)$ & $21(84.0 \%)$ & $4(16.0 \%)$ \\
Common iliac lymph node & $28(11.2 \%)$ & $8(7.3 \%)$ & $2(11.1 \%)$ & $0(0 \%)$ & $14(14.4 \%)$ \\
Internal iliac lymph node & $4(1.6 \%)$ & $0(0 \%)$ & $0(0 \%)$ & $0(0 \%)$ & $4(4.1 \%)$ \\
External iliac lymph node & $6(2.4 \%)$ & $0(0 \%)$ & $0(0 \%)$ & $6(6.2 \%)$ \\
\hline
\end{tabular}




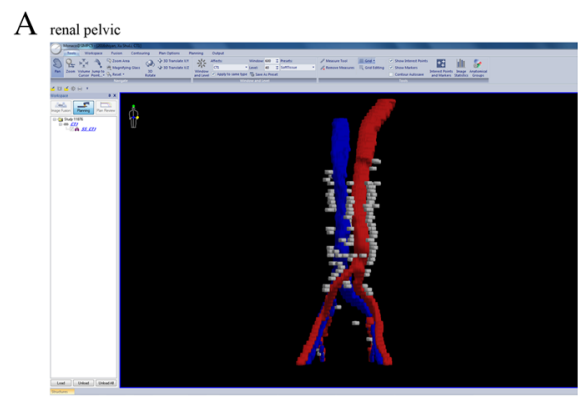

B Proximal ureter

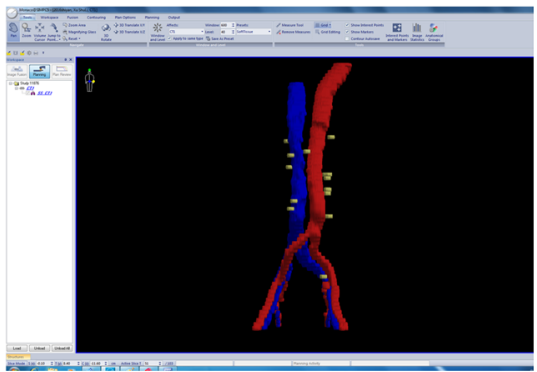

C Middle ureter

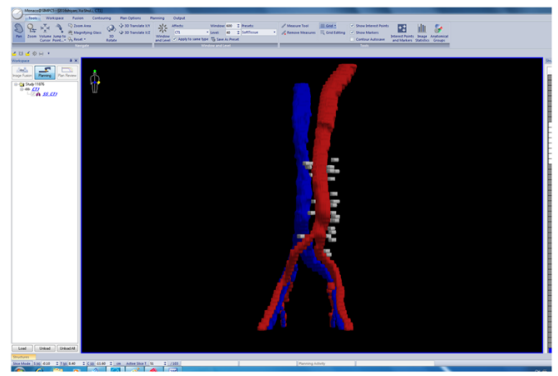

D

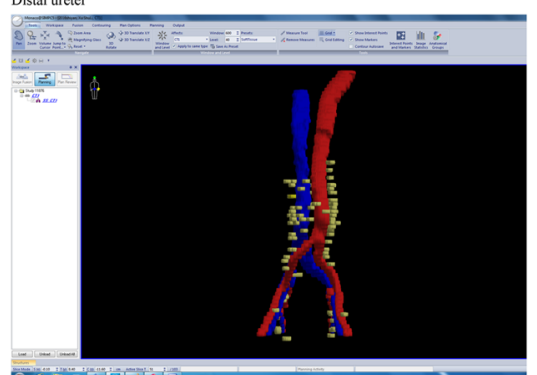

Fig. 2 Recurrence lymph node distribution map stratified by primary tumor location. a Recurrence lymph nodes of pelvic tumor. b Recurrence lymph nodes of proximal ureter tumor. c Recurrence lymph nodes of middle ureter tumor. d Recurrence lymph nodes of distal ureter tumor (red, artery; blue, vein)

recurrence rates in the pelvic cavity [17]. Surena also found upward migration of metastases to the paracaval and para-aortic regions from middle and distal ureteral tumors. Distal ureter tumors had lymph node metastases in external and internal region [13].

However, there are still no studies of the local recurrence map in UTUC patients stratified by tumor locations. Now, the clinical target volumes of UTUC patients received postoperative radiation are a wide area which includes the renal fossa, the course of the ureter to the entire bladder, and the paracaval and para-aortic lymph nodes. More than $50 \%$ of patients had acute gastrointestinal reaction side effects and hematological toxicity [37, 38]. Precise understanding of local recurrence pattern of UTUC can assist oncology clinicians to design a better radiation field in order to reduce the side effects of radiotherapy. This study provided a detailed picture of the local recurrence map of UTUC after RNU. Our results showed primary tumor locations were associated with unique patterns of local recurrence. We found the para-aortic lymph node region was the most common recurrence area for all the UTUC patients. Common iliac lymph node recurrence was the second high recurrence area. The recurrence rates in these two

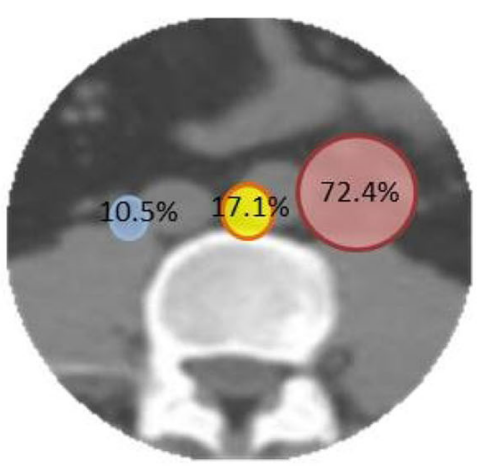

A Left UTUC

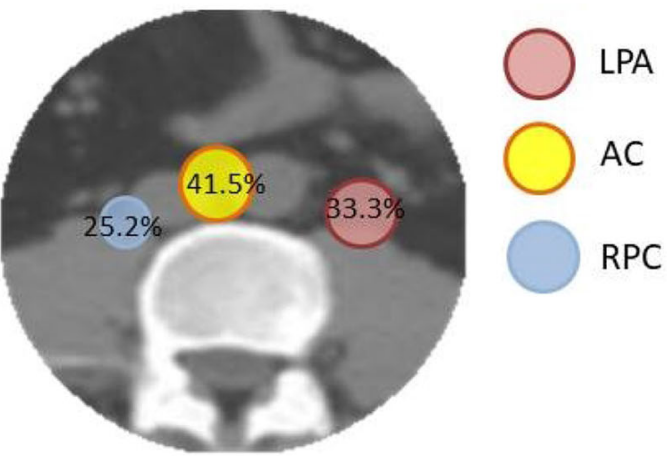

B Right UTUC

Fig. 3 Recurrence lymph node distribution ratio stratified by primary tumor site. a Recurrence lymph node distribution ratio of left UTUC patients. b Recurrence lymph node distribution ratio of right UTUC patients (red, left para-aortic; yellow, aortocaval; blue, right paracaval) 
regions were almost the same for different primary tumor locations $(P>0.05)$. In our study, distal ureter tumor had a higher recurrence rate in the external and internal regions $(P<0.05)$. This result was consistent with the metastases pattern of UTUC.

UTUC had characteristic patterns of LNM dependent on the side and anatomic location of the primary tumor, including right to left migration [13]. For the right side, dissection of the hilum, paracaval, retrocaval, and interaortocaval region would capture nearly all metastasis lymph nodes. For the left side, a hilar and para-aortic dissection would capture nearly all primary metastasis lymph nodes [12, 13]. In our study, we found that the left-side tumor had most of the recurrent lymph nodes located in the LPA region. Recurrences in the AC and $\mathrm{RPC}$ regions were rare. Right-side tumor had recurrent lymph nodes distributed in the LPA, AC, and RPC regions. This result was consistent with the LNM pattern of UTUC.

Pelvic and ureter transitional carcinoma cell (TCC) are not the same disease in terms of invasion and prognosis. The renal pelvic tumor and adjacent tissue, which might contain micro-metastases, can be completely excised within a sufficient solid barrier. The ureter is only surrounded by weak adipose tissue making it more difficult to remove a ureteral tumor within sufficient surrounding tissues. Ureter TCC was associated with a higher local or distant failure rate than renal pelvic TCC [41]. Yoo found tumor location was related with local recurrence of UTUC after surgery [15]. In their study, the local recurrence for ureter tumor patients was almost 3 times of that in pelvic tumor patients (14.3\% vs 5.2\%).In our study, we also found the same trend, the renal pelvic tumor had a relatively lower local recurrence rate than ureter tumor (HR 0.625; $P=0.047$ in univariable Cox regression analysis). Tumor bed recurrence rates were also different in pelvic and ureter tumors. Recurrence in renal fossa was only found in the renal pelvic tumor group. Ureter bed recurrence was more prevalent in ureter tumor. Whereas, patients in the renal pelvic rarely had ureter tumor bed recurrence $(P<0.05)$. Renal fossa recurrence rate of renal pelvic tumor was also lower than ureter tumor bed recurrence of ureter tumor $(22.2 \%$ vs $45.8 \%)$. This result was similar with Yoo's [15]. They found ureter tumor location was associated with surgical bed recurrence, the recurrence rate was almost 4 times of pelvic tumor $(8.1 \%$ vs $2.1 \%, P=0.011)$.

However, there were still some limitations to our study. First, this was a retrospective study. The definitive locations of recurrence sites were dependent on positive medical image scans taken during the follow-up period. Second, in this study, local recurrence sites were based on medical images, and there was no pathological verification of the recurrence sites.

\section{Conclusions}

Our study for the first time illustrated the risk factors and site-specific local recurrence pattern stratified by tumor location in UTUC patients. To our understanding, this study is the first serry to map the local failure sites in patients with UTUC after radical surgery. Due to some limitations, there is a need to include more cases and to conduct a larger-sample prospective study in the future.

\section{Supplementary information}

Supplementary information accompanies this paper at https://doi.org/10. 1186/s12957-020-01877-W.

Additional file 1: Supplementary Table. Patient clinical and pathological characteristic

\section{Abbreviations}

UTUC: Upper tract urothelial carcinoma; LVI: Lymphovascular invasion; PET: Positron emission tomography; RNU: Radical nephroureterectomy; TURBT: Transurethral resection of bladder tumor; LND: Lymph node dissection; LNM: Lymph node metastasis; TCC: Transitional carcinoma cell; LPA: Left para-aortic; AC: Aortocaval; RPC: Right paracaval

\section{Acknowledgements}

Not applicable

\section{Authors' contributions}

XY Li: Project development, data collection, data analysis, manuscript writing M Cui, SB Qin, D Fang,TZ Zhu, and HZ Li: Data collection

XB Gu: Data analysis

$\mathrm{KL}$ Yang: Manuscript writing

D Wang and XS Li: Project development

LQ Zhou and XS Gao: Project development, data analysis, manuscript writing.

The author(s) read and approved the final manuscript.

\section{Funding}

The study was funded by the Scientific Research Seed Fund of Peking University First Hospital 2018SF084

\section{Availability of data and materials}

The datasets used and/or analyzed during the current study are available from the corresponding author on reasonable request.

\section{Ethics approval and consent to participate}

The study received the ethics approval by the Ethics Committee of Peking University First Hospital (no. 2016-1253). All procedures performed in studies involving human participants were in accordance with the ethical standards of the Ethics Committee of Peking University First Hospital and with the 1964 Helsinki Declaration and its later amendments or comparable ethical standards

Consent for publication

Not applicable

\section{Competing interests}

The authors declare that they have no competing interests.

\section{Author details}

'Department of Radiation Oncology, Peking University First Hospital, Peking University, Beijing, China. ${ }^{2}$ Department of Urology, Peking University First Hospital, Peking University, Beijing, China. ${ }^{3}$ Department of Medical Imaging, Peking University First Hospital, Beijing, China. ${ }^{4}$ Department of Radiation Oncology, Rush University Medical Center , Chicago, USA. 
Received: 31 December 2019 Accepted: 11 May 2020 Published online: 30 May 2020

\section{References}

1. Genega EM, Porter CR: Urothelial neoplasms of the kidney and ureter. An epidemiologic, pathologic, and clinical review. Am J Clin Pathol 2002, 117 Suppl:S36-48.

2. Chou $\mathrm{YH}$, Huang $\mathrm{CH}$. Unusual clinical presentation of upper urothelial carcinoma in Taiwan. Cancer. 1999;85(6):1342-4.

3. Yang MH, Chen KK, Yen CC, Wang WS, Chang YH, Huang WJ, Fan FS, Chiou $\mathrm{TJ}$, Liu JH, Chen PM. Unusually high incidence of upper urinary tract urothelial carcinoma in Taiwan. Urology. 2002;59(5):681-7.

4. Chen $\mathrm{CH}$, Dickman KG, Moriya M, Zavadil J, Sidorenko VS, Edwards KL, Gnatenko DV, Wu L, Turesky RJ, Wu XR, et al. Aristolochic acid-associated urothelial cancer in Taiwan. Proceedings of the National Academy of Sciences of the United States of America. 2012;109(21):8241-6.

5. Lai MN, Wang SM, Chen PC, Chen YY, Wang JD. Population-based casecontrol study of Chinese herbal products containing aristolochic acid and urinary tract cancer risk. J Natl Cancer Inst. 2010;102(3):179-86.

6. Li CC, Chang TH, Wu WJ, Ke HL, Huang SP, Tsai PC, Chang SJ, Shen JT, Chou $\mathrm{YH}$, Huang $\mathrm{CH}$. Significant predictive factors for prognosis of primary upper urinary tract cancer after radical nephroureterectomy in Taiwanese patients. European urology. 2008;54(5):1127-34.

7. Roupret M, Zigeuner R, Palou J, Boehle A, Kaasinen E, Sylvester R, Babjuk M, Oosterlinck W: [European guidelines for the diagnosis and management of upper urinary tract urothelial cell carcinomas: 2011 update. European Association of Urology Guideline Group for urothelial cell carcinoma of the upper urinary tract]. Actas Urol Esp 2012, 36(1):2-14.

8. Wu CF, Pang ST, Chen CS, Chuang CK, Chen Y, Lin PY: The impact factors on prognosis of patients with pT3 upper urinary tract transitional cell carcinoma. J Urol 2007, 178(2):446-450, dicussion 450.

9. Jang NY, Kim IA, Byun SS, Lee SE, Kim JS. Patterns of failure and prognostic factors for locoregional recurrence after radical surgery in upper urinary tract transitional cell carcinoma: implications for adjuvant radiotherapy. Urol Int. 2013;90(2):202-6.

10. Ozsahin M, Zouhair A, Villa S, Storme G, Chauvet B, Taussky D, Gouders D, Ries G, Bontemps P, Coucke PA, et al. Prognostic factors in urothelial renal pelvis and ureter tumours: a multicentre Rare Cancer Network study. Eur J Cancer. 1999;35(5):738-43.

11. Xie J, Zhang XB, Wen J, Zhang YS, Li HZ. Comparison of clinicopathological features in metastatic upper tract urothelial carcinoma and urothelial bladder cancer. Int Urol Nephrol. 2016;48(4):481-7.

12. Kondo T, Nakazawa H, Ito F, Hashimoto Y, Toma H, Tanabe K. Primary site and incidence of lymph node metastases in urothelial carcinoma of upper urinary tract. Urology. 2007;69(2):265-9.

13. Matin SF, Sfakianos JP, Espiritu PN, Coleman JA, Spiess PE. Patterns of lymphatic metastases in upper tract urothelial carcinoma and proposed dissection templates. The Journal of urology. 2015;194(6):1567-74.

14. Catton CN, Warde P, Gospodarowicz MK, Panzarella T, Catton P, McLean M, Milosevic M. Transitional cell carcinoma of the renal pelvis and ureter: outcome and patterns of relapse in patients treated with postoperative radiation. Urologic Oncol. 1996;2(6):171-6.

15. Yoo S, You D, Jeong IG, Hong B, Hong JH, Ahn H, Kim CS. Impact of tumor location on local recurrence after nephroureterectomy for upper tract urothelial carcinoma: implications for adjuvant radiotherapy. Clin Genitourin Cancer. 2017;15(2):e199-204.

16. Dominguez-Escrig JL, Peyronnet B, Seisen T, Bruins HM, Yuan CY, Babjuk M, Böhle A, Burger M, Compérat EM, Gontero P, et al. Potential benefit of lymph node dissection during radical nephroureterectomy for upper tract urothelial carcinoma: a systematic review by the European Association of Urology guidelines panel on non-muscle-invasive bladder cancer. Eur Urol Focus. 2019:5(2):224-41.

17. Tanaka N, Kikuchi E, Kanao K, Matsumoto K, Kobayashi H, Ide H, Miyazaki Y, Obata J, Hoshino K, Shirotake S, et al. Metastatic behavior of upper tract urothelial carcinoma after radical nephroureterectomy: association with primary tumor location. Ann Surg Oncol. 2014;21(3):1038-45.

18. Rouprêt $M$, Babjuk $M$, Compérat E, Zigeuner R, Sylvester RJ, Burger $M$, Cowan NC, Gontero P, Van Rhijn BWG, Mostafid AH, et al. European Association of Urology guidelines on upper urinary tract urothelial carcinoma: 2017 update. European urology. 2018;73(1):111-22.
19. Wein AJ, Kavoussi LR, Novick AC, Partin AW, CA. P: Campbell-Walsh urology 9th ed 2007.

20. Scheidler J, Hricak H, Yu KK, Subak L, Segal MR. Radiological evaluation of lymph node metastases in patients with cervical cancer A meta-analysis. Jama. 1997;278(13):1096-101.

21. Williams AD, Cousins C, Soutter WP, Mubashar M, Peters AM, Dina R, Fuchsel F. McIndoe GA, deSouza NM: Detection of pelvic lymph node metastases in gynecologic malignancy: a comparison of CT, MR imaging, and positron emission tomography. AJR Am J Roentgenol. 2001;177(2):343-8.

22. Bipat S, Glas AS, van der Velden J, Zwinderman AH, Bossuyt PM, Stoker J. Computed tomography and magnetic resonance imaging in staging of uterine cervical carcinoma: a systematic review. Gynecol Oncol. 2003; 91(1):59-66.

23. Lengele $B$, Scalliet $P$. Anatomical bases for the radiological delineation of lymph node areas. Part III: Pelvis and lower limbs. Radiother Oncol. 2009; 92(1):22-33.

24. Takiar V, Fontanilla HP, Eifel PJ, Jhingran A, Kelly P, lyer RB, Levenback CF, Zhang Y, Dong L, Klopp A. Anatomic distribution of fluorodeoxyglucoseavid para-aortic lymph nodes in patients with cervical cancer. International journal of radiation oncology, biology, physics. 2013;85(4):1045-50.

25. Margulis V, Shariat SF, Matin SF, Kamat AM, Zigeuner R, Kikuchi E, Lotan Y, Weizer A, Raman JD, Wood CG. Outcomes of radical nephroureterectomy: a series from the Upper Tract Urothelial Carcinoma Collaboration. Cancer. 2009;115(6):1224-33.

26. Munoz JJ, Ellison LM. Upper tract urothelial neoplasms: incidence and survival during the last 2 decades. The Journal of urology. 2000;164(5):1523-5.

27. Fang D, Xiong GY, Li XS, Chen XP, Zhang L, Yao L, He ZS, Zhou LQ. Pattern and risk factors of intravesical recurrence after nephroureterectomy for upper tract urothelial carcinoma: a large Chinese center experience. J Formos Med Assoc. 2014;113(11):820-7.

28. Seisen T, Granger B, Colin P, Leon P, Utard G, Renard-Penna R, Comperat E, Mozer $\mathrm{P}$, Cussenot $\mathrm{O}$, Shariat SF, et al. A systematic review and metaanalysis of clinicopathologic factors linked to intravesical recurrence after radical nephroureterectomy to treat upper tract urothelial carcinoma. Eur Urol. 2015;67(6):1122-33.

29. Wang Q, Zhang T, Wu J, Wen J, Tao D, Wan T, Zhu W. Prognosis and risk factors of patients with upper urinary tract urothelial carcinoma and postoperative recurrence of bladder cancer in central China. BMC Urol. 2019;19(1):24.

30. Fang D, Zhang L, Li X, Yu W, Singla N, Zhao G, Xiong G, Song Y, He Q, He Z, et al. Presence of concomitant non-muscle-invasive bladder cancer in Chinese patients with upper tract urothelial carcinoma: risk factors, characteristics, and predictive value. Ann Surg Oncol. 2015;22(8):2789-98.

31. Hung SY, Yang WC, Luo HL, Hsu CC, Chen YT, Chuang YC. Segmental ureterectomy does not compromise the oncologic outcome compared with nephroureterectomy for pure ureter cancer. Int Urol Nephrol. 2014; 46(5):921-6.

32. Burger M, Shariat SF, Fritsche H-M, Martinez-Salamanca Jl, Matsumoto K, Chromecki TF, Ficarra V, Kassouf W, Seitz C, Pycha A, et al. No overt influence of lymphadenectomy on cancer-specific survival in organconfined versus locally advanced upper urinary tract urothelial carcinoma undergoing radical nephroureterectomy: a retrospective international, multiinstitutional study. World J Urol. 2011;29(4):465-72.

33. Pearce SM, Pariser JJ, Patel SG, Steinberg GD, Shalhav AL, Smith ND: The effect of surgical approach on performance of lymphadenectomy and perioperative morbidity for radical nephroureterectomy. Urol Oncol 2016, 34(3):121.e115-121.e121.121E121.

34. Tamhankar AS, Patil SR, Ahluwalia P, Gautam G. Current status of lymphadenectomy during radical nephroureterectomy for upper tract urothelial cancer-yes, no or maybe? Indian J Surg Oncol. 2018;9(3):418-26.

35. Roscigno M, Brausi M, Heidenreich A, Lotan Y, Margulis V, Shariat SF, Van Poppel $H$, Zigeuner R. Lymphadenectomy at the time of nephroureterectomy for upper tract urothelial cancer. Eur Urol. 2011;60(4): 776-83.

36. Huang YC, Chang YH, Chiu KH, Shindel AW, Lai CH. Adjuvant radiotherapy for locally advanced upper tract urothelial carcinoma. Sci Rep. 2016;6:38175.

37. Jwa E, Kim YS, Ahn H, Kim CS, Lee JL, Kim SO, S DOA: Adjuvant radiotherapy for stage III/IV urothelial carcinoma of the upper tract. Anticancer Res 2014, 34(1):333-38.

38. Chen B, Zeng ZC, Wang GM, Zhang L, Lin ZM, Sun LA, Zhu TY, Wu LL, Zhang JY, Ji Y. Radiotherapy may improve overall survival of patients with 
$\mathrm{T} 3 / \mathrm{T} 4$ transitional cell carcinoma of the renal pelvis or ureter and delay bladder tumour relapse. BMC cancer. 2011;11:297.

39. Kim M, Kim JK, Lee J, Kim YS, Lee JL, Kwak C, Jeong CW, Byun SS, Lee SC, Ohyama C, et al. Adjuvant treatments for advanced stage, non-metastatic upper tract urothelial carcinoma: a multicenter study. International journal of radiation oncology, biology, physics. 2019;104(4):819-27.

40. Edward Halperin, Perez C, Brady L: Perez and Brady's principles and practice of radiation oncology. 2007:2368.

41. Park S, Hong B, Kim CS, Ahn H. The impact of tumor location on prognosis of transitional cell carcinoma of the upper urinary tract. J Urol. 2004;171(2 Pt 1):621-5.

\section{Publisher's Note}

Springer Nature remains neutral with regard to jurisdictional claims in published maps and institutional affiliations.

Ready to submit your research? Choose BMC and benefit from:

- fast, convenient online submission

- thorough peer review by experienced researchers in your field

- rapid publication on acceptance

- support for research data, including large and complex data types

- gold Open Access which fosters wider collaboration and increased citations

- maximum visibility for your research: over $100 \mathrm{M}$ website views per year

At BMC, research is always in progress.

Learn more biomedcentral.com/submissions 